\title{
Prognostic factors in patients undergoing pulmonary resection for sarcomatoid carcinomas of the lung
}

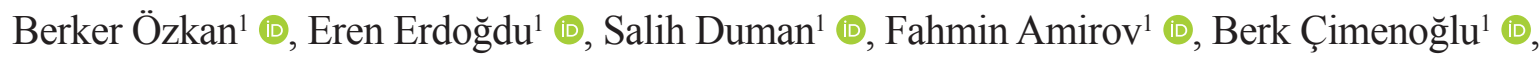

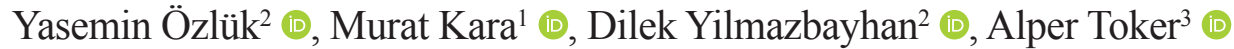 \\ ${ }^{1}$ Department of Thoracic Surgery, İstanbul University School of Medicine, İstanbul, Turkey \\ ${ }^{2}$ Department of Pathology, İstanbul University School of Medicine, İstanbul, Turkey \\ ${ }^{3}$ Department of Cardiovascular and Thoracic Surgery, West Virginia University Heart and Vascular Institute, Morgantown, USA
}

\begin{abstract}
Background: Pulmonary sarcomatoid carcinomas are very rare lung neoplasms, and no consensus exists regarding their optimal treatment. The prognosis of sarcomatoid carcinomas has been reported to be unfavorable compared with non-small-cell lung cancers; however, prognostic factors in patients undergoing surgery for sarcomatoid carcinomas remain unclear.
\end{abstract}

Aims: To analyze clinicopathologic prognostic factors and survival outcomes in patients who underwent surgery for pulmonary sarcomatoid carcinoma.

Study Design: Retrospective cross-sectional study.

Methods: We designed a retrospective cross-sectional study in patients who underwent surgery for pulmonary sarcomatoid carcinomas and statistically analyzed the prognostic factors regarding clinicopathologic features with respect to survival outcomes.

Results: We had a total of 44 patients with sarcomatoid carcinoma who had pulmonary resection. Sex distribution was 34 (77\%) males and 10 $(22.7 \%)$ females, which was determined by declaration. The mean age of patients was $57.3 \pm 16$ years with a median of 60 years. The 5-year progression-free survival and overall survival rates were $59 \%$ and $58 \%$, respectively. The 5-year survival rates were significantly different for tumors $>5 \mathrm{~cm}(P=0.044)$, tumorstatus $(\mathrm{T})(P=0.016)$, lymph node status $(\mathrm{N})(P=0.005)$, and pathologic tumor-node-metastasis (TNM) stage $(P=0.0001)$. However, histologic subtype $(P=0.628)$ and adjuvant treatment $(P=0.804)$ did not have any significant effect on survival. Similarly, the significant prognostic factors in univariate analysis were tumor size $(P=0.085)$, T status $(P=0.005), \mathrm{N}$ status $(P=0.028)$, and pathologic TNM stage $(P=0.0001)$. Multivariate analysis showed only T status $(P=0.058), \mathrm{N}$ status $(P=0.018)$, and pathologic TNM stage $(P=0.019)$ as independent prognostic factors, with statistical power of $87 \%, 43.1 \%$ and $21.2 \%$.

Conclusion: Surgery appears to be an optimal treatment with favorable outcomes for patients with pulmonary sarcomatoid carcinoma. Patients with small tumors at earlier stages are very likely to benefit from surgery, regardless of histologic subtype.

\section{INTRODUCTION}

Pulmonary sarcomatoid carcinoma (PSC) is a very uncommon type of non-small-cell lung cancer (NSCLC) with biphasic histopathologic features, which shows both carcinomatous and sarcomatous components. The most recent WHO classification of lung tumors classifies these tumors into five variants, namely, pleomorphic, spindle cell, giant cell, pulmonary blastoma, and carcinosarcoma. ${ }^{1}$

Scientific data are very limited regarding PSC, because they are extremely rare tumors consisting of $0.1-0.4 \%$ of all lung cancers. ${ }^{1}$ We are aware of a few reports regarding the prognostic factors in PSC. ${ }^{2-6}$ Among these, the largest up-to-date information coming from the Surveillance, Epidemiology, and End Results (SEER) database reported that patients with PSC presented with further stages and had poorer survival rates compared with other NSCLC cases. ${ }^{3}$ Although patients with PSC appear to benefit from surgical resection, the effects of chemotherapy remain controversial. Some authors reported that these tumors showed resistance to conventional chemotherapy ${ }^{7,8}$ and no response to palliative chemotherapy in advanced disease. ${ }^{9}$ On the other hand, adjuvant chemotherapy after surgical resection have been reported to have better results on survival. ${ }^{5}$ The optimal choice of treatment and prognosis are still under investigation for these extremely rare tumors of the lung.

Here, we present a retrospective cross-sectional study to analyze clinicopathologic prognostic factors and survival outcomes in patients who underwent surgery for PSC.

Address for Correspondence: Berk Çimenoğlu, Department of Thoracic Surgery, İstanbul University School of Medicine, İstanbul, Turkey

e-mail: berkcimenoglu@hotmail.com

Received: July 7, 2020 Accepted: September 22, 2020 •DOI: 10.4274/balkanmedj.galenos.2020.2020.7.45

Available at www.balkanmedicaljournal.org

ORCID iDs of the authors: B.Ö. 0000-0003-2157-4778; E.E. 0000-0001-8153-0107; S.D. 0000-0001-5755-7449; F.A.0000-0003-1710-9988; B.Ç. 0000-0002-9123-8203; Y.Ö. 00000002-7191-0488; M.K. 0000-0002-8429-774X; D.Y. 0000-0002-4836-567X; A.T. 0000-0002-8317-2339.

Cite this article as:

Özkan B, Erdoğdu E, Duman S, et al. Prognostic factors in patients undergoing pulmonary resection for sarcomatoid carcinomas of the lung. Balkan Med J. 2021;38(2):104-110.

Copyright@Author(s) - Available online at http://balkanmedicaljournal.org/ 


\section{MATERIAL AND METHODS}

\section{Data collection}

Of 2,654 patients with NSCLC, a total of 44 patients with PSC confirmed with biopsy were operated at our department from 2002 to 2019. All medical records were collected from both the clinical cancer and pathologic databases. Patients with incomplete data, who were lost to follow-up or had in-hospital mortality within 30 days after operation, were excluded from the study. The ethics committee of İstanbul University Medical Faculty approved this study (approval number 2019/1540). Written informed consent was obtained from all patients.

All patients underwent a staging work-up, including computed tomography of the chest and abdomen, magnetic resonance imaging of the head, and bone scintigraphy, whereas positron emission tomography (PET) was also adopted as a foundation stone in staging work-up in recent years. Patients who presented with radiologically enlarged mediastinal lymph nodes underwent invasive procedures such as fiberoptic bronchoscopy with trans bronchial needle aspiration, endobronchial ultrasound, or mediastinoscopy. All patients were staged on the basis of the 8th edition of the TNM staging system of lung cancer.

\section{Histopathologic examination}

Two experienced pathologists re-evaluated all resected material on the basis of the recent WHO 2015 classification of lung tumors, which categorizes sarcomatoid carcinomas into five subtypes, namely, pleomorphic carcinoma, spindle cell carcinoma, giant cell carcinoma, pulmonary carcinosarcoma, and pulmonary blastoma. ${ }^{1} \mathrm{Pleo}-$ morphic carcinoma is a differentiated NSCLC featuring spindle and giant cells or a carcinoma consisting of mere spindle and giant cells. In contrast, spindle cell carcinoma consists of spindle cells only, which is similar to pleomorphic carcinoma in terms of spindle cells. Giant cell carcinoma is formed completely of highly pleomorphic giant cells. Pulmonary carcinosarcoma is a malign lesion exhibiting biphasic combination of regular NSCLC and genuine sarcoma fea-

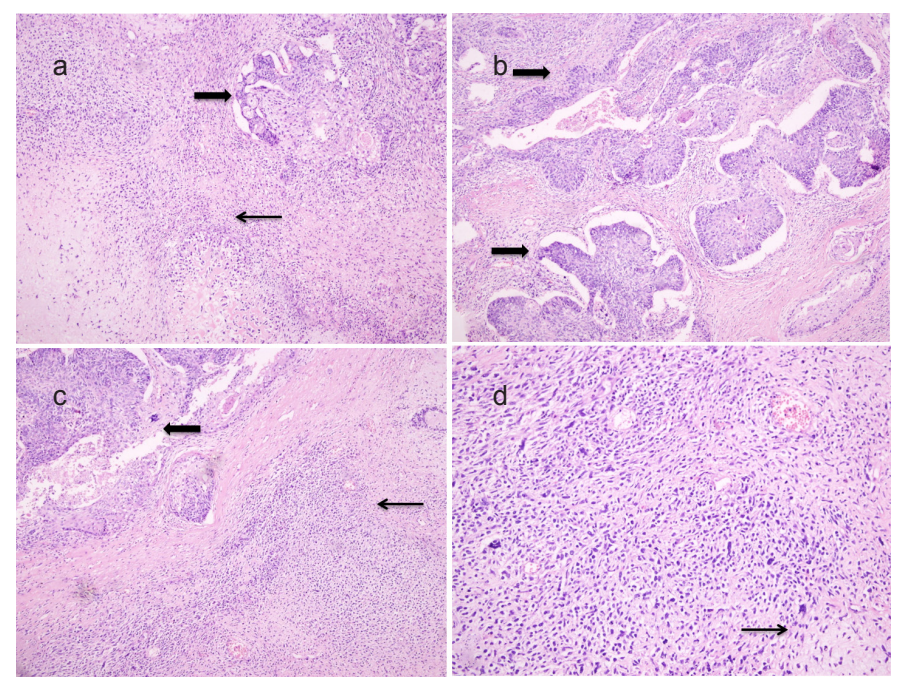

FIG. 1. (a-d). A carcinosarcoma showing both squamous cell carcinoma (black arrows) and osteosarcoma (arrows) components (hematoxylin and eosin). turing differentiated portion of malignant cartilage, bone, or skeletal muscle. ${ }^{10}$ The carcinomatous part of a carcinosarcoma is generally a squamous cell carcinoma, adenocarcinoma, or a large cell carcinoma. However, the sarcomatous part is generally a poorly differentiated spindle cell carcinoma that exhibits sarcomatous differentiation. These areas generally show rhabdomyosarcoma features; however, osteosarcoma or chondrosarcoma features may also be encountered (Figure 1). The last variant, pulmonary blastoma, is also a biphasic tumor with primitive epithelial part that may look like a well-differentiated fetal adenocarcinoma and primitive mesenchymal stroma that may contain malignant heterologous elements.

\section{Statistical analysis}

All results were evaluated with the Statistical Package for the Social Sciences version 24.0 (IBM SPSS Corp.; Armonk, NY, USA). Age, sex determined by declaration, SUVmax values, resection type, surgical procedure, tumor size, tumor status, nodal status, histologic subtype, pathologic TNM (pTNM) stage, and adjuvant treatment were included in the assessment of prognostic factors. Age, SUVmax values, and tumor size were categorized as a high or low on the basis of the median value. Surgical procedure was also classified according to the extent of the resection. Lobectomy with chest wall resection, bilobectomy, and pneumonectomy were included in the procedures as extended resections.

Cancer-specific survival was described as the period between cancer diagnosis and exitus or the latest date that the patient was known to be alive. Progression-free survival (PFS) is the period between surgery and the first recorded local and/or regional recurrence or distant metastasis. The cumulative survival rates were calculated by the Kaplan-Meier method, and the significance was assessed by the log-rank test. The Cox proportional hazards model was applied for univariate and multivariate analysis to confirm the prognostic impact of the factors on survival. Predictors in the univariate analysis with a significance level of 0.1 were included in the multivariate analysis. Power analysis was also applied to the significant parameters of multivariate analysis. Statistical significance was accepted as $P$ value below 0.05 .

\section{RESULTS}

\section{Clinicopathologic Features}

Patients were 34 (77\%) males and 10 (22.7\%) females. The mean age of patients was $57.3 \pm 16$ years, with a median of 60 years (range: 4-78) (Table 1). Among these patients, 27 (61.4\%) were smokers. They had a history of smoking with a mean $42.8 \pm 22.8$ packs/year and a median of 40 packs/year.

Right upper lobe was the most common tumor localization in 18 (40.7\%) patients, followed by left upper lobe in $16(36.4 \%)$ patients. Among these patients, 6 (13.6\%) cases had a Pancoast tumor. Tumor localization was central in 17 (38.6\%) patients (Figure 2). SUVmax value was available in $29(65.9 \%)$ patients. The mean of SUVmax value is $18.8 \pm 11.7$, with a median value of 16 (2-60). Preoperative diagnosis was available in $11(25 \%)$ patients. Neoadjuvant treatment had been initiated in $6(13.6 \%)$ patients. Chemoradiotherapy in four patients, chemotherapy alone in one patient, and radiotherapy alone in one patient were the neoadjuvant treatment regimens. 
TABLE 1. Clinicopathologic features of the patients with pulmonary sarcomatoid carcinomas

\begin{tabular}{|c|c|c|}
\hline & Mean \pm SD & $\%$ \\
\hline Age (years) & $57.3 \pm 16$ & \\
\hline \multicolumn{3}{|l|}{ Sex } \\
\hline Male & 34 & 77.3 \\
\hline Female & 10 & 22.7 \\
\hline Smoking history (pack-year) & $42.8 \pm 22.8$ & \\
\hline \multicolumn{3}{|l|}{ Tumor localization } \\
\hline Right upper lobe & 18 & 40.7 \\
\hline Right middle lobe & 1 & 2.3 \\
\hline Right lower lobe & 6 & 13.6 \\
\hline Left upper lobe & 16 & 36.4 \\
\hline Left lower lobe & 3 & 6.8 \\
\hline \multicolumn{3}{|l|}{ Localization } \\
\hline Central & 17 & 38.6 \\
\hline Peripheral & 27 & 61.4 \\
\hline SUVmax & $18.8 \pm 11.7$ & \\
\hline \multicolumn{3}{|l|}{ Operation Type } \\
\hline Wedge & 1 & 2.2 \\
\hline Lobectomy $(+/-)$ & 34 & 77.2 \\
\hline Standard & 23 & 52.2 \\
\hline Sleeve Lobectomy & 1 & 2.2 \\
\hline + Chest wall resection & 8 & 18.1 \\
\hline+ Chest wall + vertebrae resection & 2 & 4.5 \\
\hline Bilobectomy $(+/-)$ & 3 & 6.8 \\
\hline Standard & 2 & 4.5 \\
\hline + Chest wall & 1 & 2.2 \\
\hline Pneumonectomy (+/-) & 6 & 13.6 \\
\hline Standard & 4 & 9 \\
\hline+ Atrial resection & 1 & 2.2 \\
\hline Intrapericardial & 1 & 2.2 \\
\hline Tumors size & $57.7 \pm 29.4$ & \\
\hline \multicolumn{3}{|l|}{ Histology } \\
\hline Pleomorphic & 23 & 52.3 \\
\hline Spindle Cell & 9 & 20.5 \\
\hline Giant Cell & 7 & 15.9 \\
\hline Carcinosarcoma & 3 & 6.8 \\
\hline Pulmonary blastoma & 2 & 4.5 \\
\hline \multicolumn{3}{|l|}{ pT Stage } \\
\hline $\mathrm{T} 1$ & 7 & 15.9 \\
\hline $\mathrm{T} 2$ & 16 & 36.4 \\
\hline $\mathrm{T} 3$ & 10 & 22.7 \\
\hline $\mathrm{T} 4$ & 11 & 25 \\
\hline \multicolumn{3}{|l|}{ pN Stage } \\
\hline No & 28 & 63.6 \\
\hline N1 & 13 & 29.5 \\
\hline N2 & 3 & 6.8 \\
\hline \multicolumn{3}{|l|}{ pTNM } \\
\hline I & 11 & 25 \\
\hline II & 15 & 34.1 \\
\hline III & 17 & 38.6 \\
\hline IV & 1 & 2.3 \\
\hline \multicolumn{3}{|l|}{ Recurrence } \\
\hline Distant & 7 & 15.9 \\
\hline Locoregional & 6 & 13.6 \\
\hline Local & 3 & 6.8 \\
\hline
\end{tabular}

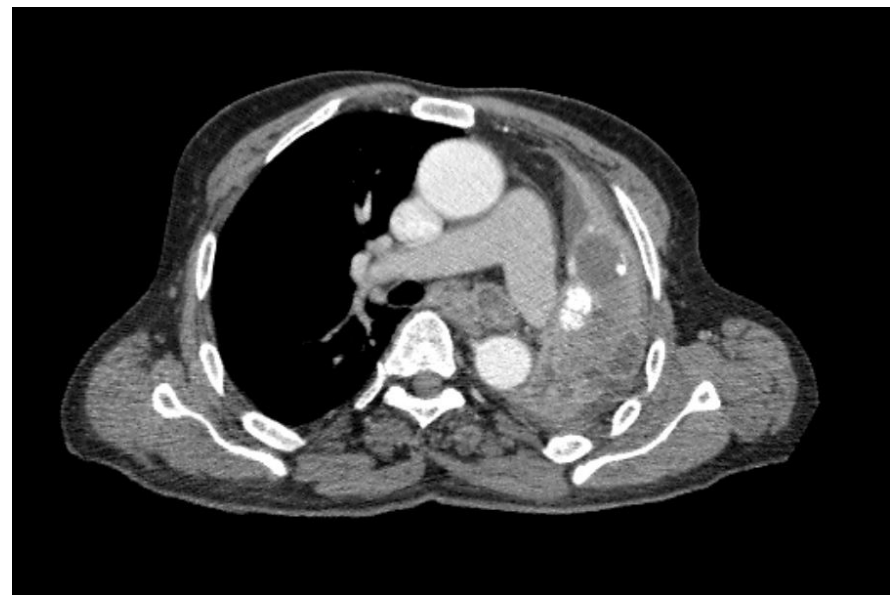

FIG. 2. A left-sided centrally located tumor in a 69-year-old male patient who was confirmed to have carcinosarcoma showing $70 \%$ of squamous cell carcinoma and $30 \%$ of osteosarcoma components.

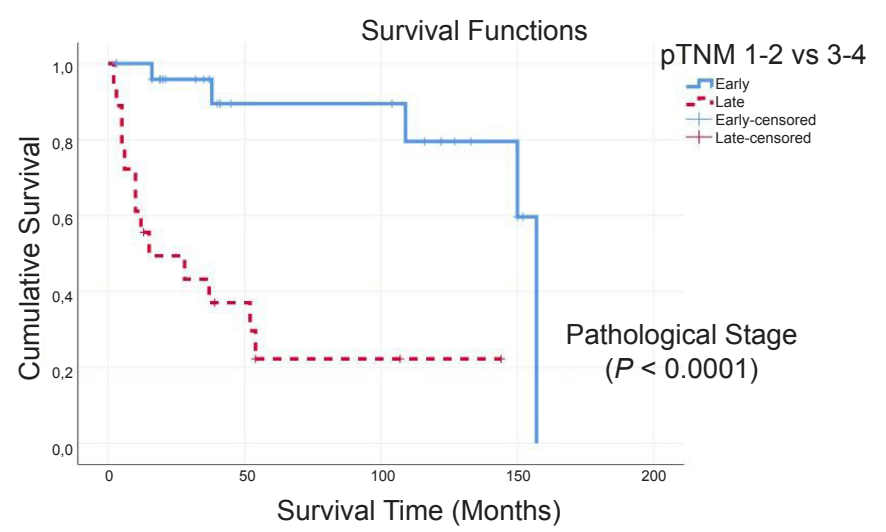

FIG. 3. Kaplan-Meier analysis of the patients with respect to adjuvant treatment.

The most common surgical procedure was lobectomy in 23 $(52.2 \%)$ patients, followed by lobectomy with chest wall resection in $8(18.1 \%)$ patients. A total of $14(31.8 \%)$ patients underwent an extended resection. The mean of histopathologic tumor size was $57.7 \pm 29.4 \mathrm{~mm}$, with a median value of $5 \mathrm{~cm}$ (17-140). The most common histologic subtype was pleomorphic carcinoma in $23(52.3 \%)$ patients, followed by spindle cell in $9(20.5 \%)$ patients. pTNM staging was stage 1 in $11(25 \%)$ patients, stage 2 in $15(34.1 \%)$ patients, stage 3 in $17(38.6 \%)$ patients, and stage 4 in $1(2.3 \%)$ patient.

A total of $40(87 \%)$ patients received adjuvant chemo and/or radiotherapy. Adjuvant chemotherapy and chemoradiotherapy have been initiated in $31(70.5 \%)$ and $9(20.5 \%)$ patients, respectively. In contrast, $4(9 \%)$ patients have received neither chemotherapy nor chemoradiotherapy. The mean follow-up time was 53 months, with a median of 37 months (range: 2-157 months). A total of 16 $(43.2 \%)$ patients had recurrence. Distant metastasis was the most common recurrence type in $7(15.9 \%)$ patients, followed by locoregional and local recurrence in $6(13.6 \%)$ and $3(6.8 \%)$ patients, respectively. 
TABLE 2. Prognostic differences in subgroups of clinicopathologic features in patients with sarcomatoid carcinoma

\begin{tabular}{|c|c|c|c|c|c|}
\hline Clinicopathologic features & No. of patients $(\%)$ & $\begin{array}{l}\text { 5-Year progression - } \\
\text { free survival }(\%)\end{array}$ & $P$ & $\begin{array}{l}\text { 5-Year overall } \\
\text { survival (\%) }\end{array}$ & $P$ \\
\hline Total & 44 & 59 & & 58 & \\
\hline \multicolumn{6}{|l|}{ Age (year) } \\
\hline$\leq 60$ & $22(50)$ & 52 & & 55 & \\
\hline$>60$ & $22(50)$ & 66 & 0.769 & 65 & 0.640 \\
\hline \multicolumn{6}{|l|}{ Sex } \\
\hline Male & $34(77)$ & 63 & & 62 & \\
\hline Female & $10(23)$ & 50 & 0.795 & 45 & 0.573 \\
\hline \multicolumn{6}{|l|}{ SUVmax value } \\
\hline$\leq 16$ & $13(45)$ & 45 & & 50 & \\
\hline$>16$ & $16(55)$ & 71 & 0.239 & 65 & 0.218 \\
\hline \multicolumn{6}{|l|}{ Resection type } \\
\hline Wedge & $1(2)$ & - & & - & \\
\hline Lobectomy & $24(56)$ & 72 & & 72 & \\
\hline Bilobectomy & $2(4)$ & - & & - & \\
\hline Resection + Chest wall resection & $11(25)$ & 45 & & 45 & \\
\hline Pneumonectomy & $6(13)$ & -0.513 & - & 0269 & \\
\hline \multicolumn{6}{|l|}{ Surgical procedure } \\
\hline$\leq$ Lobectomy & $24(55)$ & 72 & & 72 & \\
\hline > Lobectomy & $20(45)$ & 43 & 0.135 & 40 & 0.074 \\
\hline \multicolumn{6}{|l|}{ Tumor size (mm) } \\
\hline$\leq 50$ & $22(50)$ & 72 & & 71 & \\
\hline$>50$ & $22(50)$ & 43 & 0.093 & 40 & 0.044 \\
\hline \multicolumn{6}{|l|}{ T stage } \\
\hline $\mathrm{T} 1$ & $7(16)$ & 71 & & 57 & \\
\hline $\mathrm{T} 2$ & $16(36)$ & 73 & & 76 & \\
\hline $\mathrm{T} 3$ & $10(23)$ & 70 & & 64 & \\
\hline $\mathrm{T} 4$ & $11(25)$ & 24 & 0.020 & 27 & 0.016 \\
\hline \multicolumn{6}{|l|}{ T stage } \\
\hline $\mathrm{T} 1+\mathrm{T} 2+\mathrm{T} 3$ & $33(75)$ & 72 & & 70 & \\
\hline $\mathrm{T} 4$ & $11(25)$ & 24 & 0.002 & 27 & 0.002 \\
\hline \multicolumn{6}{|l|}{ Nodal involvement } \\
\hline No & $28(63)$ & 65 & & 68 & \\
\hline $\mathrm{N} 1$ & $13(30)$ & 60 & & 58 & \\
\hline $\mathrm{N} 2$ & $3(7)$ & 0 & 0.005 & 0 & 0.005 \\
\hline \multicolumn{6}{|l|}{ Nodal involvement } \\
\hline No & $28(64)$ & 65 & & 68 & \\
\hline $\mathrm{N} 1+\mathrm{N} 2$ & $16(36)$ & 48 & 0.150 & 26 & 0.021 \\
\hline \multicolumn{6}{|l|}{ Histologic subtype } \\
\hline Pleomorphic & $23(52)$ & 68 & & 60 & \\
\hline Spindle cell & $9(20)$ & 27 & & 35 & \\
\hline Giant cell & $7(16)$ & 57 & & 57 & \\
\hline Carcinosarcoma & $3(7)$ & - & & - & \\
\hline Pulmonary blastoma & $2(5)$ & - & 0.827 & - & 0.628 \\
\hline
\end{tabular}


TABLE 2. Prognostic differences in subgroups of clinicopathologic features in patients with sarcomatoid carcinoma (Continued)

\begin{tabular}{|c|c|c|c|c|c|}
\hline Clinicopathologic features & No. of patients $(\%)$ & $\begin{array}{l}\text { 5-Year progression - } \\
\text { free survival }(\%)\end{array}$ & $P$ & $\begin{array}{l}\text { 5-Year overall } \\
\text { survival }(\%)\end{array}$ & $P$ \\
\hline \multicolumn{6}{|l|}{ Pathologic stage } \\
\hline 1 & $11(25)$ & 76 & & 87 & \\
\hline 2 & $15(34)$ & 92 & & 92 & \\
\hline 3 & $17(39)$ & 25 & & 23 & \\
\hline 4 & $1(2)$ & 0 & $<0.0001$ & 0 & $<0.0001$ \\
\hline \multicolumn{6}{|l|}{ Pathologic stage } \\
\hline $1+2$ & $26(59)$ & 85 & & 89 & \\
\hline $3+4$ & $18(41)$ & 24 & $<0.0001$ & 22 & $<0.0001$ \\
\hline \multicolumn{6}{|l|}{ Adjuvant treatment } \\
\hline Present & $40(9)$ & 57 & & 56 & \\
\hline Absent & $4(91)$ & 75 & 0.603 & 75 & 0.804 \\
\hline \multicolumn{6}{|l|}{ Adjuvant treatment } \\
\hline Chemotherapy & $35(87)$ & 62 & & 64 & \\
\hline Chemoradiotherapy & $5(13)$ & 0 & 0.134 & 25 & 0.320 \\
\hline
\end{tabular}

TABLE 3. Univariate analysis of the prognostic factors by Cox proportional hazards regression model

\begin{tabular}{|c|c|c|c|c|c|c|}
\hline \multirow[b]{2}{*}{ Variable } & \multicolumn{3}{|c|}{ Progression-free survival } & \multicolumn{3}{|c|}{ Overall survival } \\
\hline & Relative risk & $95 \%$ confidence interval & $P$ & Relative risk & $95 \%$ confidence interval & $P$ \\
\hline Age $($ year $)(\leq 60$ versus $>60)$ & 1.151 & $0.444-2.988$ & 0.772 & 1.263 & $0.471-3.384$ & 0.642 \\
\hline Sex (female versus male) & 1.146 & $0.402-3.265$ & 0.798 & 1.349 & $0.472-3.853$ & 0.576 \\
\hline SUVmax value $(\leq 16$ versus $>16)$ & 1.911 & $0.597-6.117$ & 0.275 & 2.180 & $0.608-7.811$ & 0.231 \\
\hline $\begin{array}{l}\text { Surgical procedure } \\
\text { (> Lobectomy versus } \leq \text { lobectomy) }\end{array}$ & 1.890 & $0.745-4.794$ & 0.180 & 2.125 & $0.813-5.553$ & 0.124 \\
\hline Tumor size $(\mathrm{mm})(>50$ versus $\leq 50)$ & 2.227 & $0.841-5.892$ & 0.107 & 2.463 & $0.884-6.861$ & 0.085 \\
\hline $\mathrm{T}$ stage (T4 versus $\mathrm{T} 1+\mathrm{T} 2+\mathrm{T} 3)$ & 3.913 & $1.495-10.243$ & 0.005 & 4.096 & $1.521-11.034$ & 0.005 \\
\hline Nodal status (N1 + N2 versus N0) & 1.944 & $0.763-4.951$ & 0.164 & 3.000 & $1.127-7.982$ & 0.028 \\
\hline $\begin{array}{l}\text { Pathologic stage } \\
\text { (stage } 3+4 \text { versus stage } 1+2 \text { ) }\end{array}$ & 7.628 & $2.437-23.873$ & $<0.0001$ & 10.035 & $2.783-36.182$ & $<0.0001$ \\
\hline Adjuvant treatment (absent versus present) & 1.690 & $0.223-12.802$ & 0.611 & 1.291 & $0.170-9.806$ & 0.805 \\
\hline
\end{tabular}

TABLE 4. Multivariate analysis of the prognostic factors by Cox proportional hazards regression model

\begin{tabular}{|c|c|c|c|c|c|c|}
\hline \multirow[b]{2}{*}{ Variable } & \multicolumn{3}{|c|}{ Progression-free survival } & \multicolumn{3}{|c|}{ Overall survival } \\
\hline & Relative risk & $95 \%$ confidence interval & $P$ & Relative risk & $95 \%$ confidence interval & $P$ \\
\hline Tumor size $(\mathrm{mm})(>50$ versus $\leq 50)$ & 5.141 & $0.866-30.514$ & 0.072 & 2.924 & $0.489-17.467$ & 0.239 \\
\hline T Stage (T4 versus $\mathrm{T} 1+\mathrm{T} 2+\mathrm{T} 3)$ & 3.791 & $0.655-21.942$ & 0.137 & 6.554 & $0.935-45.923$ & 0.058 \\
\hline Nodal status (N1 + N2 versus N0) & 2.408 & $0.789-7.352$ & 0.123 & 5.518 & $1.343-22.665$ & 0.018 \\
\hline $\begin{array}{l}\text { Pathologic stage } \\
(\text { stage } 3+4 \text { versus stage } 1+2)\end{array}$ & 11.766 & $2.494-55.501$ & 0.002 & 7.288 & $1.391-38.189$ & 0.019 \\
\hline
\end{tabular}

\section{Survival outcomes and prognosis}

The 1-, 3-, and 5-year PFS rates were $71 \%, 59 \%$, and 59\%, respectively, whereas the 1-, 3-, and 5-year overall survival rates were $81 \%, 73 \%$, and $58 \%$, respectively.

There was no significant difference between survival rates regarding the subgroups of age, sex determined by declaration, subgroups of SUVmax values, resection type, surgical procedure, histologic subtype, and adjuvant treatment (Figure 3). However, we found that subgroups of tumor size $(P=0.044)$, T status $(P=0.016)$, N status $(P=0.005)$, and pTNM stage $(P<0.0001)$ (Figure 4$)$ showed significantly different survival rates (Table 2 ).

Univariate analysis showed subgroups of tumor size $(P=0.085)$, T status $(P=0.005), \mathrm{N}$ status $(P=0.028)$, and pTNM stage $(P$ $<0.0001)$ as prognostic factors (Table 3$)$. However, multivariate 


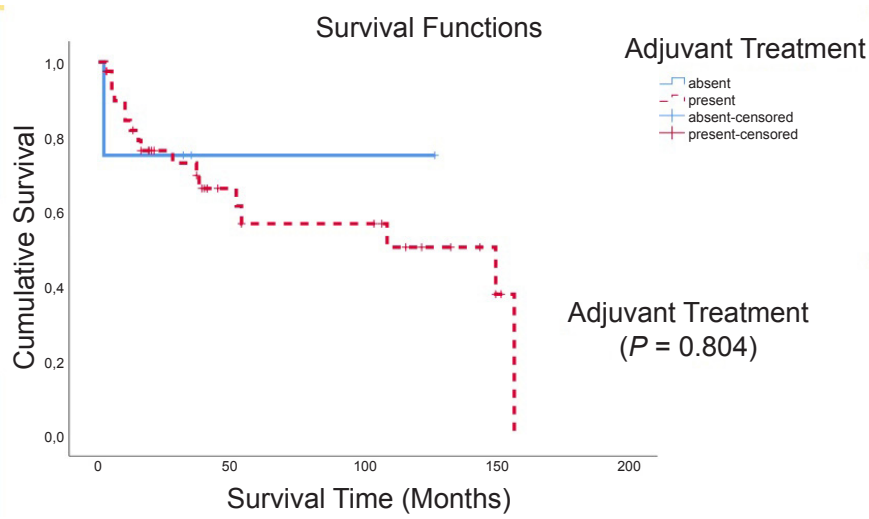

FIG. 4. Kaplan-Meier analysis of the patients with respect to pTNM. pTNM, pathologic TNM

analysis uncovered only T status $(P=0.058), \mathrm{N}$ status $(P=0.018)$, and pTNM stage $(P=0.019)$ as independent prognostic factors on survival (Table 4). Post-hoc analysis with 95\% confidence interval shows statistical power of $87 \%, 43.1 \%$, and $21.2 \%$ for $\mathrm{T}$ stage, nodal involvement, and pathologic stage, respectively.

\section{DISCUSSION}

PSC is histologically defined as poorly differentiated NSCLC, particularly squamous cell carcinoma, adenocarcinoma, or undifferentiated NSCLC featuring a component of sarcoma or sarcoma-like elements with at least $10 \%$ spindle and/or giant cells or a carcinoma featuring only spindle and giant cells. ${ }^{1,11}$ These tumors appear mostly in heavy smoker males in their 60 s; however, pulmonary blastoma occurs in their 40 s equally in both sexes. ${ }^{2,12}$ PSC is most often located centrally with an endobronchial extension without any infiltration to the bronchial wall; however, they may show extensive invasion to the surrounding lung parenchyma. The heterogeneity of these tumors and the likelihood of the biopsy specimens often showing only one component may also result in a non-diagnostic endobronchial or transthoracic biopsy. Likewise, only $11(25 \%)$ patients had a preoperative histologic diagnosis in our series. Some reports show that PSCs have a higher capability of 18-flouro-2-deoxy-d-glucose uptake in PET scan than other NSCLCs, which might be highly suggestive of a sarcomatoid carcinoma. ${ }^{2,4,13}$ Similarly, the mean of SUVmax value in our study was $18.8 \pm 11.7$, which was consistent with the finding above.

Surgery appears to be the treatment of choice for PSC; however, these aggressive tumors have poor outcomes. They are frequently slow-growing large tumors that often present at later stages of the disease. They have a potential to invade bronchial structures and vasculature on hilum or the chest wall laterally. ${ }^{2}$ Thus, these patients are commonly being subject to extended resections such as bilobectomy, chest wall resection, pneumonectomy, or sleeve lobectomy for these tumors. ${ }^{2,4}$ Similarly, a total of 18 (41\%) patients underwent an extended resection in our series. Tumors with endobronchial localization have a comparably better prognosis because peripheral tumors tend to metastasize early and widely. The surgical outcome is not favorable, with a 5-year survival rate ranging from $12 \%$ to $49 \%{ }^{3,6,7}$ Some authors have reported 1-, 3-, and 5-year survival rates as low as $45 \%, 28 \%$, and $20 \%$, respectively, for PSC after surgery, which were worse than those for NSCLC. ${ }^{2,5,14,15}$ Our survival rates were much better compared with these series. The survival rates were $81 \%, 73 \%$, and $58 \%$, respectively, for 1,3 , and 5 years. A series from South Korea, which had a predominant histologic subtype of pleomorphic sarcoma with a rate of $90 \%$, showed a 5-year survival rate of $54.3 \%$, which was very similar to our results. ${ }^{4}$ Similar to that report, the vast majority of the patients had pleomorphic sarcoma in our series with a rate of $52 \%$, and there were only $3(7 \%)$ cases with carcinosarcomas. In addition, our analysis did not reveal histologic subtype as a prognostic factor on survival, similar to that study. However, the most recent SEER database showed that carcinosarcomas had an unfavorable survival outcome among other subtypes of PSC. ${ }^{3}$ In contrast, Huang et al. ${ }^{5}$ reported that tumor size was an independent prognostic factor. Likewise, Roesel et al. ${ }^{2}$ found $\mathrm{T}$ status and age as significant prognostic factors. We also found that $\mathrm{T}$ status had a prognostic impact on survival; however, our study showed that age was not a significant factor. Koss et al. ${ }^{16}$ claimed that the tumor size was strongly related to survival; however, the stage of the disease did not affect survival. In their study, the 5-year survival rates of patients with a tumor size less than $6 \mathrm{~cm}$ were found to be $40 \%$ and that of patients with a tumor size greater than $6 \mathrm{~cm}$ were found to be $10 \%$. In contrast, $\mathrm{T}$ status and pathologic stage both had a prognostic impact in our series. The 5-year survival rates of patients with tumor sizes less and more than $5 \mathrm{~cm}$ were statistically different in our series. Park et al. ${ }^{4}$ also emphasized that the T status and pathologic stage were significant predictors of survival. Similarly, post-hoc analysis with $95 \%$ confidence interval shows statistical power of $87 \%$ for $\mathrm{T}$ stage in our study, which clarified $\mathrm{T}$ stage as a significant predictor of survival even in such a small number of series. In contrast, Pelosi et al. ${ }^{17}$ reported that the aggressive nature of the sarcomatoid component might increase the angiogenic activity and cell motility of these tumors. They suggest that the sarcomatoid component is closely related to the tumor size, which might have a negative impact on survival.

The non-surgical treatment of PSC remains arguable. Vieira et al. ${ }^{7}$ and Yendamuri et $\mathrm{al}^{8}{ }^{8}$ reported that PSC is unresponsive to chemotherapy. A chemotherapy regimen targeting the sarcomatous component should be selected for PSC because the sarcomatous component of PSC is more progressively metastatic. Furthermore, PSC might be irresponsive to palliative chemotherapy in advanced disease. ${ }^{9}$ Huang et al..$^{5}$ states that postoperative chemotherapy is beneficial in patients with PSC. Huang et al. ${ }^{5}$ also found that both surgery and adjuvant chemotherapy had a significant effect on survival. However, only surgery appeared to be a favorable prognostic factor, and adjuvant treatment did not have an impact on survival in our series. We found that the overall 5-year survival of patients who received adjuvant therapy was $56 \%$ and that of patients who did not receive adjuvant therapy was $50 \%$ in our series, which did not show a significant difference $(P=0.249)$. Similarly, collective data from France consisting of 93 patients showed that the high resistance to chemotherapy emphasized the need to test for new strategies through collaborative programs, and a platinum-based combination chemotherapy was more effective than monotherapy. ${ }^{6}$ 
In addition, another previous study also showed that PFS rates of patients who received platinum-based chemotherapy were similar to those of patients who did not receive platinum-based chemotherapy. ${ }^{7}$ Park et al. ${ }^{4}$ also reported similar results without any effect of either neoadjuvant or adjuvant treatment on survival. A carcinoma that undergoes a sarcomatoid diversion ends up forming a carcinosarcoma. ${ }^{3}$ Innovative treatments such as target-mediated therapies including epidermal growth factor receptor mutations have been shown to have no positive impact on survival in PSC. ${ }^{18,19}$ However, TP53 mutations are frequent in PSC, unlike KRAS and $E G F R$. In contrast, although there is scarcity of EGFR mutations in carcinosarcomas, they are shown to be related with a favorable outcome when anti-EGFR treatment is induced ${ }^{20}$ The resistance to standard chemotherapy emphasizes the necessity to spot targetable genetic variations. Likewise, the role of radiotherapy in PSC also is still uncertain and requires further randomized controlled trials. Rahouma et al. ${ }^{3}$ found a difference of only 1 month in survival between patients who received radiotherapy and those who did not. Rahuoma et al. ${ }^{3}$ reviewed a very large national database of almost $1,000,000$ patients to compare PSCs with NSCLCs with respect to clinicopathologic features and surgical outcomes. They reported that 4,987 patients with histologic diagnosis of PSC presented with more advanced stages and worse survival outcomes. They concluded that surgery provided a survival advantage for PSC. However, they also stated that these tumors had a higher risk of recurrence and should be assessed for innovative adjuvant treatment. ${ }^{3}$ Our results showed that the overall survival and disease-free survival rates were very similar, which means that patients with recurrence have a very short survival. This finding might be attributed to the lack of efficient adjuvant therapies for PSC. Fortunately, recent data showed promising effects of immunotherapy for these tumors, which show expression of PDL-1. ${ }^{21,22}$

In conclusion, PSC is a very rare lung tumor. It is most often a slow-growing tumor presenting with large size at later stages. Surgical resection may provide a favorable outcome for these tumors of any histologic subtype at earlier stages. Novel adjuvant treatments are necessary because current treatments appear to have little prognostic impact on survival.

Ethics Committee Approval: Ethics committee approval was received for this study from the Ethics Committee of İstanbul University Medical Faculty by the number 2019/1540.

Patient Consent for Publication: Written informed consent was obtained from all patients' to be published in this article.

Data-sharing Statement: N/A.

Author Contributions: Concept - B.Ö.; Design - B.Ö., M.K.; Supervision - M.K., A.T., D.Y.; Materials - E.E., F.A., B.Ç.; Data Collection and/or Processing - E.E., F.A., B.Ç.; Analysis and/or Interpretation - M.K., Y.Ö.; Literature Review -B.Ö., M.K., A.T.; Writing - B.Ö.; Critical Review - M.K., A.T.

Conflict of Interest: The authors have no conflicts of interest to declare.

Funding: The authors declared that this study had received no financial support.

\section{REFERENCES}

1. Travis WD, Brambilla E, Burke AP, Marx A, Nicholson AG. WHO Classification of Tumours of the Lung, Pleura, Thymus and Heart, 4th edn. IARC 2015; 88-94.

2. Roesel C, Terjung S, Weinrich G, et al. Sarcomatoid carcinoma of the lung: a rare histological subtype of non-small cell lung cancer with a poor prognosis even at earlier tumour stages. Interact Cardiovasc Thorac Surg. 2017;24(3):407-413. [Crossref]

3. Rahouma M, Kamel M, Narula N, et al. Pulmonary sarcomatoid carcinoma: an analysis of a rare cancer from the Surveillance, Epidemiology, and End Results database. Eur J Cardiothorac Surg. 2018;53:828-834. [Crossref]

4. Park JS, Lee Y, Han J, et al. Clinicopathologic outcomes of curative resection for sarcomatoid carcinoma of the lung. Oncology. 2011;81(3-4):206-213. [Crossref]

5. Huang SY, Shen SJ, Li XY. Pulmonary sarcomatoid carcinoma: a clinicopathologic study and prognostic analysis of 51 cases. World J Surg Oncol. 2013;11:252. [Crossref]

6. Ung M, Rouguette I, Filleron T, et al. Characteristics and clinical outcomes of sarcomatoid carcinoma of the lung. Clin Lung Cancer. 2016;17(5):391-397. [Crossref]

7. Vieira T, Girard N, Ung M, et al. Efficacy of first-line chemotherapy in patients with advanced lung sarcomatoid carcinoma. J Thorac Oncol. 2013;8(12):1574-1577. [Crossref]

8. Yendamuri S, Caty L, Pine M, et al. Outcomes of sarcomatoid carcinoma of the lung: a surveillance, epidemiology, and end results database analysis. Surgery. 2012;152(3):397-402. [Crossref]

9. Bae H-M, Min HS, Lee SH, et al. Palliative chemotherapy for pulmonary pleomorphic carcinoma. Lung Cancer. 2007;58(1):112-115. [Crossref]

10. Corrin B, Chang YL, Rossi G, et al. Sarcomatoid carcinoma. In: Travis WD, Brambilla E, Müller-Hermelink HK, Harris CC, editors. Pathology and genetics of tumours of the lung, pleura, thymus and heart (World Health Classification of Tumours). Lyon: IARC Press: 2004. P. 53-8.

11. Beasley MB, Brambilla E, Travis WD. The 2004 World Health Organization classification of lung tumors. Semin Roentgenol. 2005;40(2):90-97. [Crossref]

12. Travis WD. Sarcomatoid neoplasms of the lung and pleura. Arch Pathol Lab Med. 2010;134(11):1645-1658. [Crossref]

13. Kaira K, Endo M, Abe M, et al. Biologic correlates of ${ }^{18} \mathrm{~F}$-FDG uptake on PET in pulmonary pleomorphic carcinoma. Lung Cancer. 2011;71(2):144-150. [Crossref]

14. Martin LW, Correa AM, Ordonez NG, et al. Sarcomatous carcinoma of the lung: a predictor of poor prognosis. Ann Thorac Surg. 2007;84(3):973-980. [Crossref]

15. Maneeil K, Xue Z, Liu M, et al. Sarcomatoid Carcinoma of the Lung: The Mayo Clinic Experience in 127 Patients. Clin Lung Cancer. 2018;19(3):e323-e333. [Crossref]

16. Koss MN, Hochholzer L, Frommelt RA. Carcinosarcomas of the lung: a clinicopathological study of 66 patients. Am J Surg Pathol. 1999;23(12):1514-1526. [Crossref]

17. Pelosi G, Fraggetta F, Nappi O, et al. Pleomorphic carcinomas of the lung show a selective distribution of gene products involved in cell differentiation, cell cycle control, tumor growth, and tumor cell motility: a clinicopathologic and immunohistochemical study of 31 cases. Am J Surg Pathol. 2003;27(9):1203-1215. [Crossref]

18. Italiano A, Cortot AB, Ilie M, et al. EGFR and KRAS status of primary sarcomatoid carcinomas of the lung: implications for anti-EGFR treatment of a rare lung malignancy. Int J Cancer. 2009;125(10):2479-2482. [Crossref]

19. Leone A, Graziano P, Gasbarra R, et al. Identification of EGFR mutations in lung sarcomatoid carcinoma. Int $J$ Cancer. 2011;128:732-735. [Crossref]

20. Stiles BM, Nasar A, Hussein MK, et al. Routine molecular testing of resected early-stage lung adenocarcinoma with targeted next-generation sequencing demonstrates a high rate of actionable mutations. J Thorac Oncol. 2016;11(2):44-45. [Crossref]

21. Cimpeanu E, Ahmed J, Zafar W, et al. Pembrolizumab - emerging treatment of pulmonary sarcomatoid carcinoma: a case report. World J Clin Cases. 2020;8(1):97-102. [Crossref]

22. Matsumoto Y, Miura T, Horiuchi H, Usui K. The Successful treatment of pulmonary pleomorphic carcinoma with pembrolizumab: a case report. Case Rep Oncol. 2017;10(2):752-757. [Crossref] 